\title{
The coronary delivery of marrow stromal cells for myocardial regeneration: Pathophysiologic and therapeutic implications
}

Jih-Shiuan Wang, MD

Dominique Shum-Tim, MD

Edgar Chedrawy, MD

Ray C.-J. Chiu, MD, PhD

From the Division of Cardiothoracic Surgery, McGill University, Montreal, Quebec, Canada, and the Division of Cardiovascular Surgery, Yang-Ming University/Veterans General Hospital, Taipei, Taiwan.

Received for publication Aug 30, 2000; revisions requested Jan 16, 2001; revisions received Feb 2, 2001; accepted for publication April 6, 2001

Address for reprints: Ray C.-J. Chiu, MD, The Montreal General Hospital, 1650 Cedar Ave, Room C9-169, Montreal, Quebec, Canada H3G 1A4 (E-mail: rchiu@pobox.mcgill.ca)

J Thorac Cardiovasc Surg 2001;122:699-705 Copyright @ $\odot 2001$ by The American Association for Thoracic Surgery

$0022-5223 / 2001 \$ 35.00+0 \quad \mathbf{1 2 / 1 / 1 1 6 3 1 7}$

doi:10.1067/mtc.2001.116317
Objectives: Bone marrow stromal cells contain "adult stem cells." We tested the hypothesis that coronary-infused bone marrow stromal cells may populate the infarcted heart and undergo milieu-dependent differentiation to regenerate functional tissues with different phenotypic features.

Methods: Isogenic adult rats were used as donors and recipients to simulate autologous transplantation clinically. Myocardial infarction was created by proximal occlusion of left coronary artery in 12 recipient rats. Isolated bone marrow stromal cells were purified, expanded, and retrovirally transduced with $L a c Z$ reporter gene for cell labeling. Stromal cells were then infused into the briefly distally clamped ascending aorta of recipient rats 2 weeks after left coronary artery ligation. The hearts were harvested immediately $(n=2)$ or 4 weeks $(n=10)$ later to trace the implanted cells and identify their phenotypes.

Results: Viable cells labeled with $L a c Z$ reporter gene were identified in 8 recipient hearts. Immediately after cell infusion, the labeled cells were trapped within the coronary capillaries. After 4 weeks, they could be detected individually or in clusters within myocardial scar expressing fibroblastic phenotype or outside the infarction area with morphologic features of normal cardiomyocytes. Some were incorporated into endocardium and capillary endothelium.

Conclusions: Our findings suggest that bone marrow stromal cells can traffic through the coronary system to the injured heart and form cardiomyocytes or fibroblasts, depending on the specific microenvironment. Endothelial progenitor cells in the stromal cell population may be involved in the postinfarction neovascularization process. Whether therapeutic use of bone marrow stromal cells can improve the myocardial healing and remodeling process after infarction is worthy of further investigation.

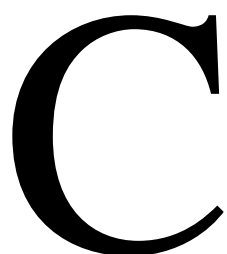

ellular cardiomyoplasty, ${ }^{1}$ wherein donor cells are transplanted into the myocardium, may augment cardiac function in myocardial disease states. Proposals to use certain sources of donor cells for cellular cardiomyoplasty, although appearing promising, are not ideal for clinical application, owing primarily to the need for fetal tissue and/or for immunosuppression. ${ }^{2-5}$ Marrow stromal cells (MSCs) constitute a separate group of stem cells other than hematopoietic stem cells in the bone marrow and have been explored as vehicles for both cell and gene therapy in recent years. ${ }^{6}$ Under controlled in vitro conditions, MSCs have been reproducibly guided to differentiate into multiple mesenchymal lineages, including those of osteocytes, chondrocytes, adipocytes, myocytes, and even cardiomyocytes. ${ }^{7,8}$ 


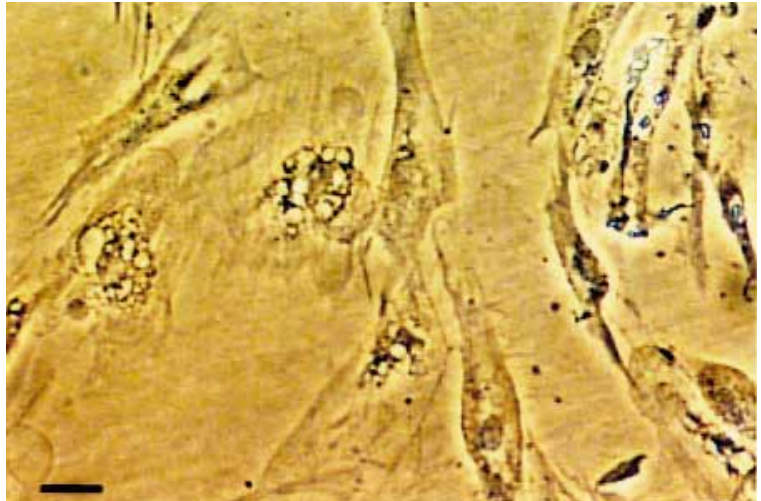

Figure 1. Morphologic features of rat MSCs in culture. Phase contrast photomicrograph of twice-passaged culture of MSCs just before implantation. Most adherent MSCs are practically fibroblastic in structure. Scale bar represents $30 \mu \mathrm{m}$.

Recently, we $\mathrm{e}^{9}$ demonstrated that the in vivo myocardial environment can support the growth and induce the cardiomyogenic differentiation of MSCs. Compared with other cell sources, MSCs seem to have many advantages for clinical use in cellular cardiomyoplasty.

Grafting of cells into the myocardium requires some form of delivery system. The choice for the routes of cell implantation may depend on the pathologic condition of the heart. Up to now, most of studies in the field of cellular cardiomyoplasty were performed by direct injection of various cells into the myocardium. ${ }^{1-5,9}$ Although implanted cells may have the ability to migrate along the ventricular surface of heart, ${ }^{10}$ this procedure covers only a limited field and may require multiple injections, either through epicardium or via the endocardium. Coronary arterial delivery of donor cells to the myocardium possesses theoretical advantages, at least for certain types of heart failure. Thus, to optimize the strategy for cell implantation, in this study we evaluated the feasibility of delivering MSCs by selective infusion into the coronary circulation. We further tested the hypothesis that MSCs infused into coronary arteries may repopulate the heart and that signals originating in the cardiac milieu could modify the developmental program of the infused MSCs. Toward this goal, we wished to confirm their residence outside the capillary bed and to observe the structural interactions between the host myocardial tissues and the implanted MSCs.

\section{Methods \\ Animals}

Male inbred Lewis rats, 200 to $250 \mathrm{~g}$, were obtained from Charles River Laboratories (Laprairie Co, Quebec, Canada). These isogenic rats were used as donors and recipients to simulate the autologous infusion of MSCs in future clinical application. All animals received humane care in compliance with the "Guide for the Care

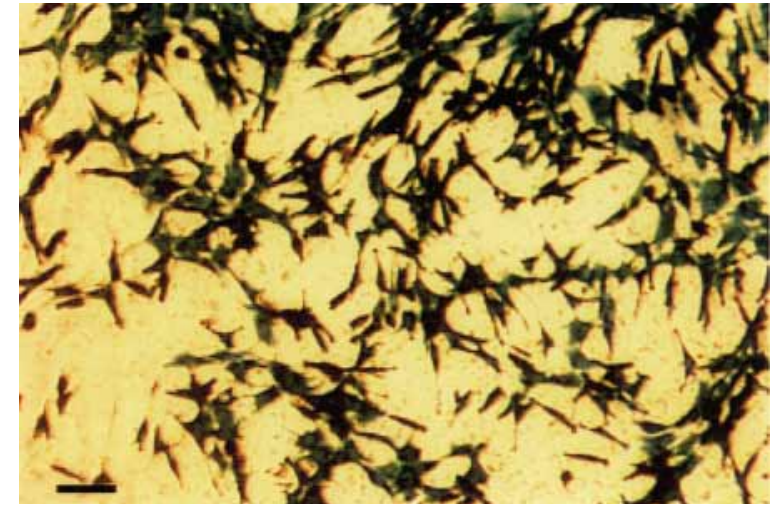

Figure 2. Histochemical staining for $\beta$-gal activity of rat MSCs in culture. The transfected MSCs showed clear staining for $\beta$-gal activity. Transfection efficiency of the MSCs was approximately $100 \%$. Scale bar represents $60 \mu \mathrm{m}$.

and Use of Laboratory Animals" prepared by the Institute of Laboratory Animal Resources, National Research Council, and published by the National Academy Press, revised 1996, and the "Guide to the Care and Use of Experimental Animals" of the Canadian Council on Animal Care.

\section{Myocardial Infarction Model}

Twelve recipient rats were anesthetized with isoflurane (MTC Pharmaceuticals, Cambridge, Ontario, Canada). Rats were intubated and their lungs were ventilated at 85 breaths/min. The heart was exposed via a left thoracotomy incision. The left coronary artery was identified and ligated proximally with a 7-0 polypropylene suture. Regional myocardial ischemia was confirmed by the rapid occurrence of akinesia in the area at risk. The wound was then closed.

\section{Isolation and Culture of MSCs}

Isolation and primary culture of MSCs from the femoral and tibial bones of donor rats were performed according to Caplan's method. ${ }^{11}$ After an overdose with pentobarbital $(100 \mathrm{mg} / \mathrm{kg}$ given intraperitoneally), the femoral and tibial bones were collected. Both ends of the bones were cut away from the diaphyses. The bone marrow plugs were hydrostatically expelled from the bones with complete medium. The marrow plugs were disaggregated and the dispersed cells were centrifuged and resuspended twice in complete medium. These cells in $10 \mathrm{~mL}$ of complete medium were then introduced into tissue culture dishes. Medium was completely replaced every 3 days and the nonadherent cells were discarded. Each primary culture was replated twice (first and second passages) to 3 new plates when the cell density within colonies became $80 \%$ to $90 \%$ confluent. After the twice-passaged cells became nearly confluent, they were harvested and used for the coronary infusion experiments.

\section{Medium}

The cells were routinely cultured in complete medium consisting of Dulbecco's modified Eagle's medium containing selected lots of $10 \%$ fetal calf serum and antibiotics $(100 \mathrm{U} / \mathrm{mL}$ penicillin $\mathrm{G}, 100$ 


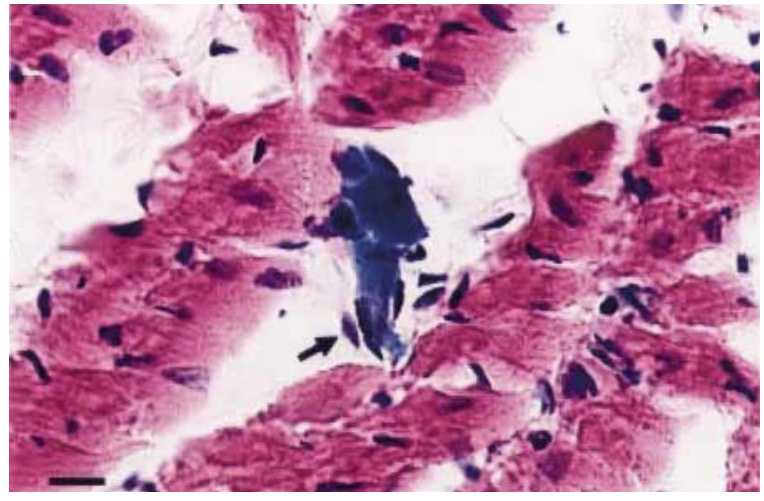

Figure 3. $\beta$-Gal-positive cells trapped within a coronary capillary immediately after injection of MSCs. Staining for $\beta$-gal activity followed by hematoxylin and eosin staining. Arrow, A capillary endothelial cell. Scale bar represents $15 \mu \mathrm{m}$.

$\mu \mathrm{g} / \mathrm{mL}$ streptomycin, and $0.25 \mu \mathrm{g} / \mathrm{mL}$ amphotericin $\mathrm{B}$; all obtained from Gibco Laboratories, Grand Island, NY) at $37^{\circ} \mathrm{C}$ in a humidified atmosphere of $5 \%$ carbon dioxide.

\section{MSC Labeling}

GP+E86 murine ectropic retrovirus-packaging cells, which are derived from National Institutes of Health 3T3 mouse fibroblasts, were obtained from Dr Denis Cournoyer ${ }^{12}$ (McGill University, Montreal, Quebec, Canada). The GP+E86 cells were transfected with the purified plasmid DNA pMFG-LacZ in a 10:1 molar ratio by means of the standard calcium phosphate transfection kit (Pharmacia, Baie d'Urfe, Quebec, Canada). The LacZ gene encodes for the production of bacterial $\beta$-galactosidase ( $\beta$-gal). These cells were plated at $25 \%$ confluence for 48 hours. The second-passaged MSC growth medium was replaced with the supernatant from the GP+E86 cells (containing the replication-defective retrovirus carrying the $\beta$-gal reporter gene) to transfect the MSCs overnight and then replaced with normal complete medium for the next day. After 3 times of transfection, MSCs were then collected (approximately $2 \times 10^{6}$ cells for one infusion) and resuspended in $50 \mu \mathrm{L}$ of serum-free Dulbecco's modified Eagle's medium and stored on ice until infusion into the ascending aorta. Some culture plates were selected for histochemical staining in vitro for $\beta$-gal activity. The cells were fixed in $2 \%$ formaldehyde and $0.2 \%$ glutaraldehyde in phosphate-buffered saline solution (PBS) at $4^{\circ} \mathrm{C}$ for 5 minutes. Staining for $\beta$-gal was accomplished at $37^{\circ} \mathrm{C}$ for 16 hours in a solution containing $1 \mathrm{mg} / \mathrm{mL}$ 5-bromo-4-chloro-3indoyl- $\beta$-D-galactoside (X-gal), $2 \%$ dimethylsulfoxide, $10 \mathrm{mmol} / \mathrm{L}$ potassium ferricyanide, $10 \mathrm{mmol} / \mathrm{L}$ potassium ferrocyanide, 1 $\mathrm{mmol} / \mathrm{L}$ magnesium chloride, and $0.02 \%$ hydrogel (Nonidet $\mathrm{P}-40$ ) in PBS, pH 7.3.

\section{Infusion of MSCs}

Two weeks after the coronary ligation, the 12 recipient rats were prepared for infusion of MSCs. Anesthesia was induced and maintained as above. The rats were intubated and connected to the ventilator. The ascending aorta was exposed through an upper median
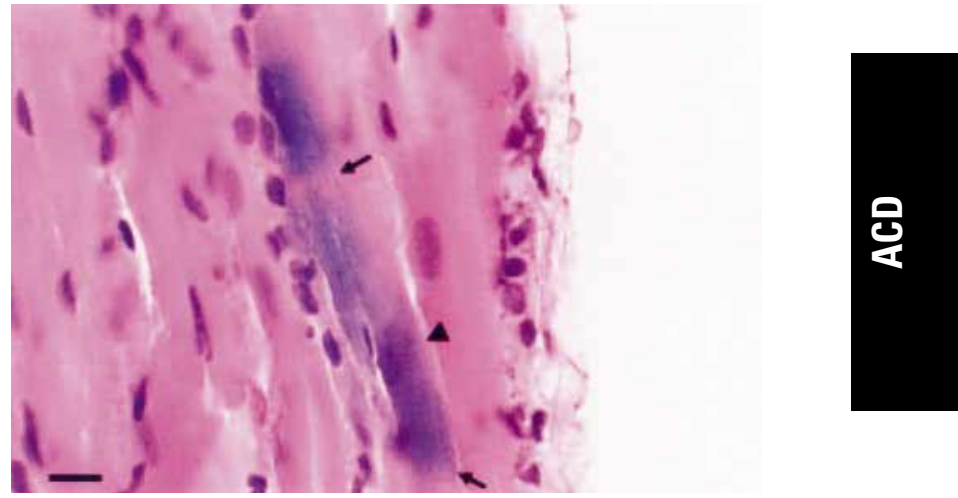

Figure 4. $\beta$-Gal-positive cells with cardiomyocyte morphologic characteristics outside infarct scar 4 weeks after injection of MSCs. Staining for $\beta$-gal activity followed by hematoxylin and eosin staining. Arrows, Intercalated disklike structure. Arrowhead, The nucleus of a $\beta$-gal-positive cell. Scale bar represents $15 \mu \mathrm{m}$.

sternotomy and looped after dissection. Under direct vision, transfected MSC suspension was then infused into the briefly distally clamped ascending aorta (about 20 seconds). After the infusion, the puncture bleeding site over the ascending aorta was controlled by compression with gauze. The wound was then closed in layers.

\section{Histology and Histochemical Staining for $\beta$-Gal Activity}

Two rats were put to death immediately after the infusion. The hearts were excised and sliced along the short axis of the left ventricle to $3-\mathrm{mm}$ thick sections in series and fixed in $2 \%$ paraformaldehyde in PBS for 2 hours. The sections were then cryoembedded in PBS overnight after protection with $20 \%$ sucrose. The other 10 rats were taken for their final experiments 4 weeks after the MSC infusion. After an overdose with pentobarbital, the hearts were exposed and injected with $100 \mathrm{~mL}$ saline solution $(0.9 \%)$ through the apex of the left ventricle and then perfusionfixed with $2 \%$ paraformaldehyde in PBS. The hearts were excised, sliced, and prepared as mentioned above. Cryosections $6 \mu \mathrm{m}$ in thickness were collected in each 3-mm section sample across a set of gelatin-coated glass slides. One of every 10 cryosections was collected for histochemical staining for $\beta$-gal activity as described above. The sections were then counterstained with hematoxylin and eosin. Tissue sections were examined with an Olympus microscope (BX-FLA; Olympus America, Inc, Huntington Station, NY). Digital images, transferred to a computer equipped with Image Pro software (Media Cybernetics, Silver Spring, Md), were subsequently printed.

\section{Histochemical Stain for Gap-Junction Protein, Connexin 43}

The gap junctions that constitute cardiac muscle-specific intercalated disks were demonstrated by histochemical stain for connexin 43, using rabbit anti-connexin antibodies (Zymed Laboratories Inc, San Francisco, Calif). Diaminobenzidine was used as a chromogen 


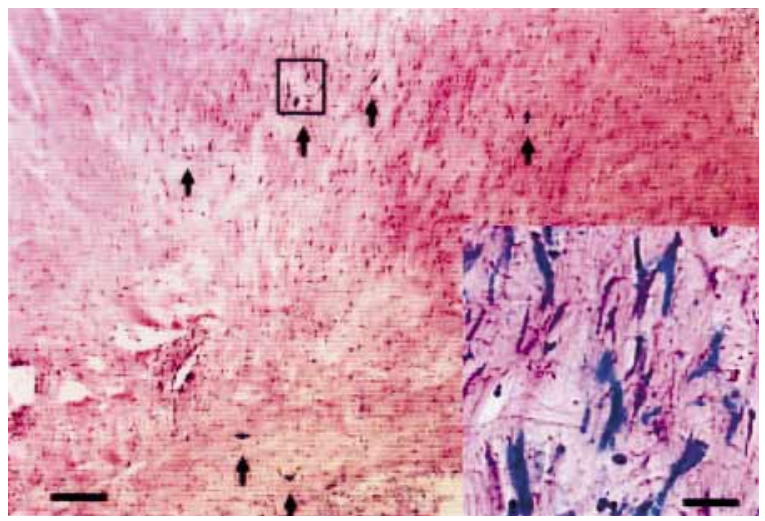

Figure 5. $\beta$-Gal-positive cells with fibroblast-like morphologic features in the myocardial scar 4 weeks after injection of MSCs. Staining for $\beta$-gal activity followed by hematoxylin and eosin staining. Arrows, $\beta$-Gal-positive cells. Scale bar represents $\mathbf{1 . 5}$ $\mathrm{mm}$. Inset, Higher magnification of the area in the square. Scale bar represents $30 \mu \mathrm{m}$.

to produce the brown color that represents gap junctions linking cardiomyocytes together. ${ }^{13}$

\section{Estimates of the Number of $\beta$-Gal-Positive Cells in the Heart}

We estimated the number of $\beta$-gal-positive cells present in the heart immediately and 4 weeks after infusion by means of Weiss's method, ${ }^{14}$ which had been validated for the rodent heart model. Estimates of cell counts reported represent the average pooled data from 2 and 6 rats put to death immediately and 4 weeks after infusion, respectively.

\section{Results}

Cultured MSCs were observed with a phase microscope to assess the level of expansion and to verify the morphologic features at each culture medium change. Most of the hematopoietic stem cells were not adherent to the culture plate and were removed with changes in medium. The adherent cells were seen as individual cells or colonies of only a few cells on day 6 ; however, they replicated rapidly and formed colonies of up to 100 cells after the first week of culture. By the end of second week, the colonies of adherent cells had expanded in size, with each colony containing several hundred to several thousand cells. Adherent MSCs from rat legs had similar morphologic characteristics, most being fibroblastic in appearance, with a few adipocytic, polygonal cells (Figure 1). This phenotype was retained throughout repeated passages under nonstimulating conditions.

We transfected twice-passaged MSCs with replicationdefective retrovirus carrying the $\beta$-gal reporter gene as cell labeling before their implantation. The transfected MSCs showed clear histochemical staining for $\beta$-gal activity

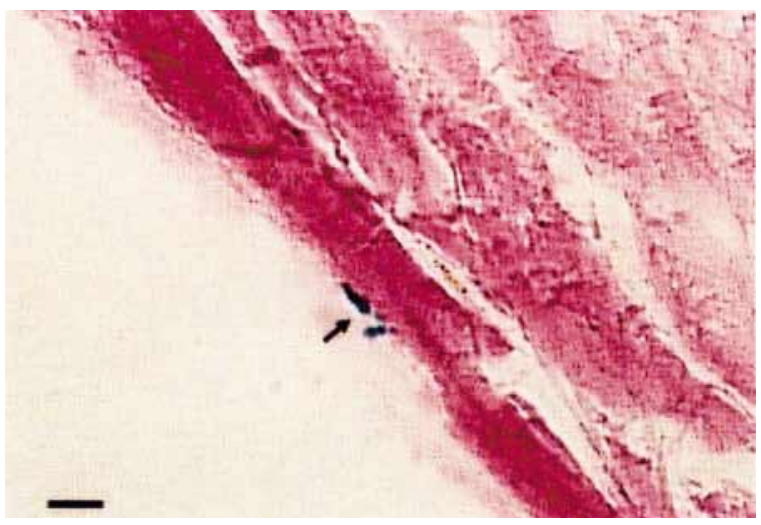

Figure 6. $\beta$-Gal-positive cells incorporated into endocardium 4 weeks after injection of MSCs. Staining for $\beta$-gal activity followed by hematoxylin and eosin staining. Arrow, Endocardium. Scale bar represents $15 \mu \mathrm{m}$.

(Figure 2). Transfection efficiency of the MSC culture was almost $100 \%$.

The rats were put to death at the following intervals after the infusion of MSCs: immediately for 2 rats and at 4 weeks for 10 rats. Gross examination of the excised hearts showed clear myocardial scar formation (about $40 \%$ of left ventricular free wall) on all 12 recipient rats. Cryosections of the specimens were selected (as detailed in the "Methods" section) for histochemical staining of $\beta$-gal activity to trace and evaluate the morphologic and phenotype changes of infused MSCs. Labeled cells could be identified in both rats that were put to death immediately after infusion of MSCs and in 6 of 10 rats put to death 4 weeks later.

Immediately after infusion of MSCs, $\beta$-gal-positive cells were consistently found in all selected sections to be trapped within the coronary capillaries surrounded by endothelial cells all over the noninfarcted area (Figure 3). Approximately 40,000 MSCs, that is, about $2 \%$ of the cells infused into the ascending aorta, were estimated to have been trapped within coronary capillaries immediately after infusion. We failed to identify any $\beta$-gal-positive cells in the infarction zone at this time. Four weeks after MSC infusion, some $\beta$-gal positive cells could be found within the normal myocardial area outside the infarct scar (Figure 4). They had centrally located nuclei and were connected among themselves and with surrounding host cardiomyocytes ( $\beta$ gal-negative cells) by intercalated disklike structures, which are characteristics of normal cardiomyocytes. However, the $\beta$-gal-positive cells also could be detected individually or in clusters within the myocardial scar (Figure 5). They appeared unorganized and scattered in the infarction scar with fibroblast-like morphologic features, similar to those of the surrounding $\beta$-gal-negative (host) fibroblast cells. Some $\beta$-gal-positive cells were found incorporated into 

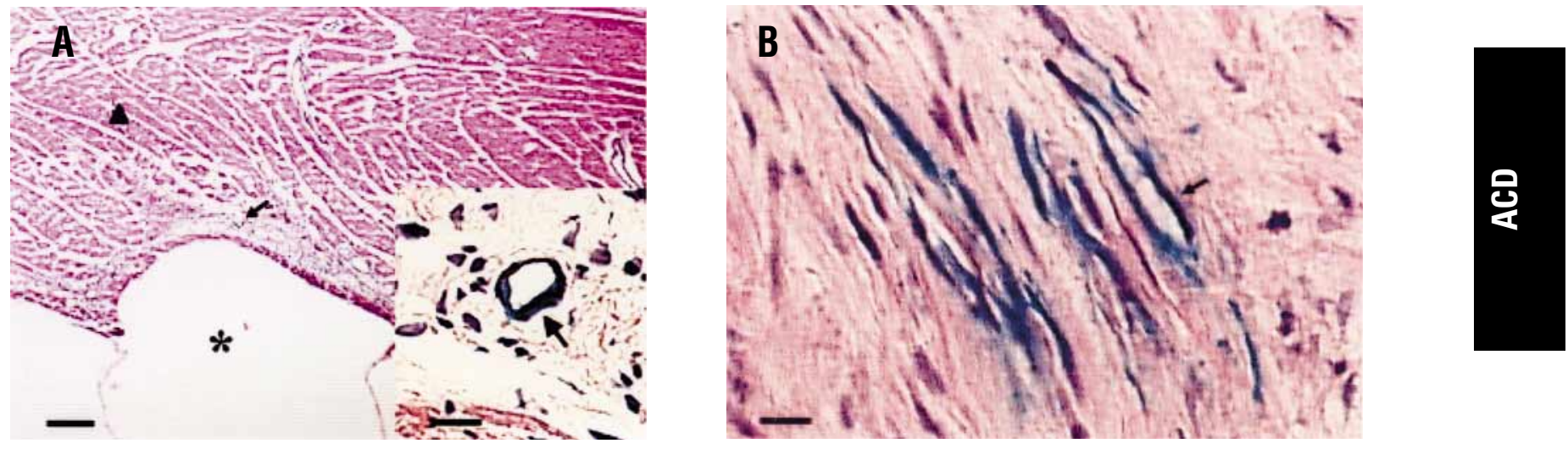

Figure 7. $\beta$-Gal-positive cells incorporated into coronary capillaries 4 weeks after injection of MSCs. Staining for $\beta$-gal activity followed by hematoxylin and eosin staining. A, Outside the infarct scar. Arrow, A capillary with $\beta$ gal-positive cells in the area of subendocardial fibrosis. Arrowhead, Normal myocardium. Asterisk, Endoventricular space. Scale bar represents $600 \mu \mathrm{m}$. Inset, Higher magnification. Arrow, The cross section of the same capillary with $\beta$-gal-positive cells. Scale bar represents $\mathbf{1 5} \mu \mathrm{m}$. B, In the infarct scar. Arrow, The oblique section of a capillary with $\beta$-gal-positive cells. Scale bar represents $15 \mu \mathrm{m}$.

endocardium (Figure 6) and coronary capillary endothelium within or outside the infarcted scar area (Figure 7, $A$ and $B$ ). Using the calculation method described above, we estimated that approximately $500 \beta$-gal-positive cells, including about 400 fibroblast-like cells in the infarcted area, 50 myocytes within normal myocardial tissue, and 50 endothelial cells all over the field, were present in one heart.

Tissue sections showing labeled cells with histologic features of cardiomyocytes (as in Figure 4) were further studied immunohistochemically by means of antibodies against connexin 43 , a major constituent protein of gap junctions in the intercalated disks of cardiac myofibers. The demonstration of such junctional structure (Figure 8) further confirms the phenotype of the differentiated labeled cells and their integration into the native cardiac myofibers.

\section{Discussion}

So that the fate of infused MSCs could be traced in this study, they were retrovirally transfected with $\beta$-gal reporter gene for cell labeling. Compared with other virus-based gene transfer, retrovirus has less immunologic response and longer gene expression. ${ }^{15}$ Such retroviral vectors are not wild-type viruses but are modified replication-defective viruses; thus, there is no risk of in vivo reinfection of neighboring cells by those escaping from damaged labeled cells. ${ }^{16}$ Furthermore, since the retroviral genes are integrated into the genome of the transfected cells, they can duplicate themselves during cell division and label the progeny of these cells as well. With the current transfection model, the transfection efficiency in culture is approximately $100 \%$ without obvious adverse effect on the cell growth. Our in vivo control studies, including infusion of MSC culture supernatant, nontransfected MSCs, or lysed transfected MSCs while performing the same readout, confirmed the specificity of this cell-labeling technique for our study (data not shown).

Immediately after the infusion, the MSCs were trapped within the coronary capillaries in the noninfarcted area. The reason we could not find MSCs in the infarct scar at this time may be related to the complete occlusion of involved coronary artery (left coronary artery). Approximately 40,000 MSCs, about $2 \%$ of the cells infused into the ascending aorta, were detected immediately after infusion. This number is lower than that of cells expected to partition to the coronary circulation (around 5\%). We suspect some cells could have leaked out of the puncture hole on the ascending aorta. Others might not have gone into the coronary circulation because we infused cells into the ascending aorta above the coronary orifices with forward blood flow. The problem of the delivery system was beyond the scope of our study in this small animal model. In larger animal models or future human studies, selective coronary catheter infusion or simply increasing the number of infused cells will readily enhance the quantity of cells delivered. However, 4 weeks after infusion, the MSCs could be found both in the infarction scar and in the noninfarcted area outside the vascular structure. The mechanism of the translocation of MSCs from the vascular lumen into the myocardial interstitium is unknown. MSCs had been shown to have the ability to migrate in the in vivo experimental model. ${ }^{17}$ They may migrate out of the vasculature and move from the noninfarcted area to the infarction scar. The other possible explanation is that scar of myocardial infarction is not completely dead tissue. Studies have shown partial restitution and 


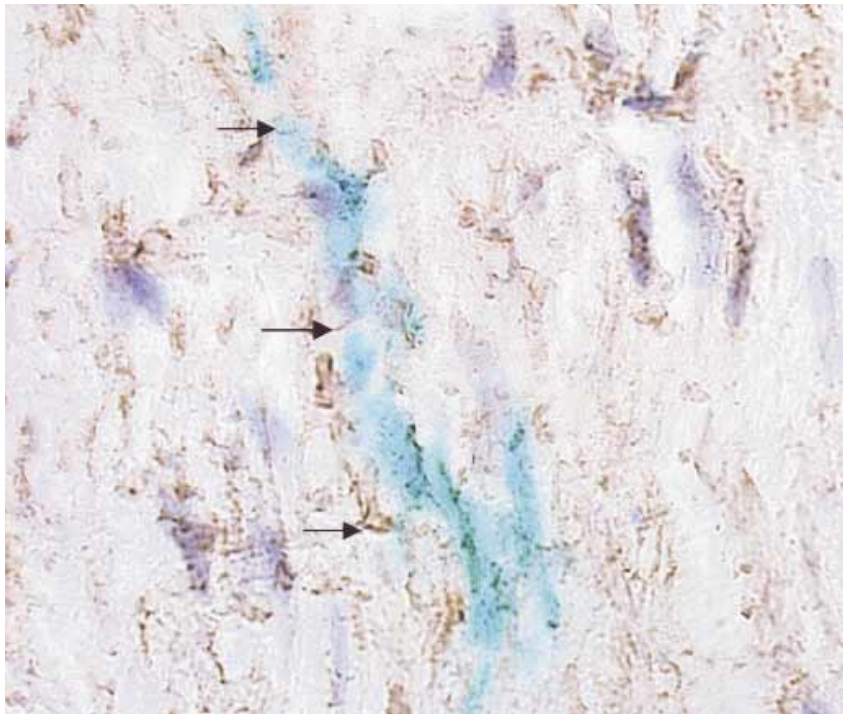

Figure 8. Immunohistochemical stain for connexin 43 in the intercalated disks (arrows), demonstrating the presence of gap junction unique to myocardium in the labeled (blue) myocytes.

function of the microvascular network within infarcted myocardial tissue, ${ }^{18}$ which may serve as a route for MSCs to engraft within the infarct scar. We noted that the number of engrafted MSCs was considerably fewer in hearts 4 weeks after infusion. We speculate that perhaps some MSCs did not migrate out of the coronary capillaries or that engrafted MSCs might not have all survived. However, further studies are required to elucidate such issues.

Nevertheless, MSCs in different myocardial microenvironments clearly have different fates. In the noninfarcted area, they expressed the phenotypes of normal cardiomyocytes and connected with surrounding host cardiomyocytes by intercalated disklike structures. In the infarct scar, they appeared primarily fibroblast-like. The mechanism of differences in development and differentiation is not fully understood. Recently, Makino and associates ${ }^{8}$ could identify a single clone of adherent fibroblast-like cells in the MSC culture which, when treated with 5-azacytidine, would differentiate into cells with some morphologic features of cardiac muscle and expression of cardiac-specific genes in vitro. MSCs have been proven to be involved in the mesengenic process for self-maintenance and repair of different mesenchymal tissues. ${ }^{19,20}$ Moreover, the progeny of MSCs expressed genes in a tissue-specific manner depending on their destination. ${ }^{19}$ This homing ability and the capability to acquire the phenotypes of different target tissues suggest that the microenvironment plays a significant role for the differentiation of these cells. Kopen, Prockop, and Phinney ${ }^{17}$ injected MSCs into neonatal mouse brains and found that these cells migrated throughout the forebrain and cerebellum. Moreover, MSCs mimic the behavior of neural progenitor cells and differentiate into astrocytes and even neurons, as indicated by the expression of neurofilament. This suggests that MSCs can produce differentiated progeny of a different embryonic dermal origin under the influence of neonatal brain microenvironment. It is our hypothesis that, in contrast to myocardial scar tissue, the normal myocardial microenvironment may enable newly arrived cells to be exposed, in an appropriate sequential manner, to various cardiomyogenic specific growth factors and differentiation molecules, such that the infused MSCs could develop into fully mature cardiomyocytes. The fibroblast-like MSCs seen in the infarction scar could have differentiated into primary fibroblasts, which are mature mesenchymal cells, or they could still maintain the multipotent differentiation ability for future maturation. Clearly, further studies are needed to assess the validity of these speculations.

In this study, we also found some $\beta$-gal-positive donor cells to differentiate into endothelium, which was incorporated into capillaries in the infarcted and noninfarcted areas. It has been shown that some cells in MSC culture are positive for factor VIII-associated antigen, ${ }^{21}$ suggesting an endothelial origin. Shi and associates ${ }^{22}$ suggested that a subset of cells localized in the bone marrow could be mobilized to the peripheral circulation and colonize endothelial flow surfaces of vascular prostheses. Takahashi and cowork$\mathrm{ers}^{23}$ further demonstrated that ischemia and cytokines could induce the mobilization of marrow-derived endothelial progenitor cells for neovascularization. In this study, we cannot prove that these capillaries incorporated with $\beta$ gal-positive donor cells are newly formed. However, these marrow-derived endothelial progenitor cells are likely to be involved in the angiogenesis and vasculogenesis in the remodeling process of myocardial infarction.

Both localized site-specific and global delivery of autologous MSCs may be of potential therapeutic benefit in view of different cardiac pathologic conditions. For example, intracoronary delivery of MSCs may be more suitable for the treatment of heart failure resulting from diffuse cardiomyopathy. Furthermore, although this animal model does not allow us to conclude that MSCs normally participate in the healing and remodeling process after myocardial infarction, our findings demonstrate that when expanded MSCs are delivered to the coronary circulation of an infarcted heart, they are capable of populating the heart and differentiating along several lineages including cardiomyocytes, fibroblasts, and endothelial cells. Thus, by extrapolating the findings of Takahashi and associates ${ }^{23}$ in limb ischemia, one may hypothesize that infarcted heart muscle could also signal mobilization of MSCs to enter the circulation and reach the coronary arteries, where they may participate in myocyte replenishment, reactive fibrosis, and 
scar formation, as well as angiogenesis, in the postinfarction pathophysiologic remodeling process, involving both the infarcted segment and the remote noninfarcted areas. Thus, further studies to elucidate the role of MSCs in myocardial infarction may lead to the possible clinical applications of MSC implantation, enabling us to therapeutically modulate the remodeling process after myocardial infarction.

\section{Conclusions}

Our findings suggest that MSCs that have the potential to traffic through the circulatory system to the injured heart are capable of forming cardiomyocytes and other types of cells, depending on the specific microenvironment. Endothelial progenitor cells in the MSC population may be involved in the postinfarction neovascularization process. Although we believe our findings reported here contribute significantly to the rapidly progressing field of stem cell therapy against myocardial damage, further investigations designed to elucidate the quantitative and functional aspects of this approach will be required, because they were not within the scope of the present study.

We appreciate the technical assistance of Minh Duong, BSc.

\section{References}

1. Chiu RCJ, Zibaitis A, Kao RL. Cellular cardiomyoplasty: myocardial regeneration with satellite cell implantation. Ann Thorac Surg. 1995;60:12-8

2. Soonpaa MH, Koh GY, Klug MG, Field LJ. Formation of nascent intercalated disks between grafted fetal cardiomyocytes and host myocardium. Science. 1994;264:98-101.

3. Li RK, Jia ZQ, Weisel RD, Mickle DAG, Zhang J, Mohabeer MK, et al. Cardiomyocytes transplantation improves heart function. Ann Thorac Surg. 1996;62:654-61.

4. Taylor DA, Atkins BZ, Hungspreugs P, Jones TR, Reedy MC, Hutcheson KA, et al. Regenerating functional myocardium: improved performance after skeletal myoblast transplantation. Nat Med. 1998;4:929-33.

5. Klug MG, Soonpaa MH, Koh GY, Field LJ. Genetically selected cardiomyocytes from differentiating embryonic stem cells form stable intracardiac grafts. J Clin Invest. 1996;98:216-24.

6. Clark BR, Jamieson C, Keating A. Human long-term bone marrow culture. Methods Mol Biol. 1997;75:249-56.

7. Pittenger MF, Mackay AM, Beck SC, Jaiswal RK, Douglas R, Mosca JD, et al. Multilineage potential of adult human mesenchymal stem cells. Science. 1999;284:143-7.
8. Makino S, Fukuda K, Miyoshi S, Konishi F, Kodama H, Pan J, et al. Cardiomyocytes can be generated from marrow stromal cells in vitro. J Clin Invest. 1999;103:697-705.

9. Wang JS, Shum-Tim D, Galipeau J, Chedrawy E, Eliopoulos N, Chiu RCJ. Marrow stromal cells for cellular cardiomyoplasty: feasibility and clinical advantages. J Thorac Cardiovasc Surg. 2000;120:9991006.

10. Connold AL, Frischknecht R, Dimitrakos M, Vrbova G. The survival of embryonic cardiomyocytes transplanted into damaged host rat myocardium. J Muscle Res Cell Motil. 1997;18:63-70.

11. Wakitani S, Saito T, Caplan AI. Myogenic cells derived from rat bone marrow mesenchymal stem cells exposed to 5-azacytidine. Muscle Nerve. 1995; 18:1417-26.

12. Momparler RL, Laliberte J, Eliopoulos N, Beausejour C, Cournoyer D. Transfection of murine fibroblast cells with human cytidine deaminase cDNA confers resistance to cytosine arabinoside. Anticancer Drugs. 1996;7:266-74.

13. Nagy JI, Li WE, Roy C, Doble BW, Gilchrist JS, Kardami E, et al. Selective monoclonal antibody recognition and cellular localization of an unphosphorylated form of connexin 43. Exp Cell Res. 1997; 236:127-36.

14. Weiss L. Biomechanical destruction of cancer cells in the heart: a rate regulator of hematogenous metastasis. Invasion Metastasis. 1988;8:228-37.

15. Onifer SM, White LA, Whittemore SR, Holets VR. In vitro labeling strategies for identifying primary neural tissue and a neuronal cell line after transplantation in the CNS. Cell Transplant. 1993;2:131-49.

16. Jaalouk DE, Eliopoulos N, Couture C, Mader S, Galipeau J. Glucocorticoid-inducible retrovector for regulated transgene expression in genetically engineered bone marrow stromal cells. Hum Gene Ther. 2000;11:1837-49.

17. Kopen GC, Prockop DJ, Phinney DG. Marrow stromal cells migrate throughout forebrain and cerebellum, and they differentiate into astrocytes after injection into neonatal mouse brains. Proc Natl Acad Sci U $S$ A. 1999;96:10711-6.

18. Huwer H, Rissland J, Vollmar B, Nikoloudakis N, Welter C, Menger $\mathrm{MD}$, et al. Angiogenesis and microvascularization after cryothermiainduced myocardial infarction: a quantitative fluorescence microscopic study in rats. Basic Res Cardiol. 1999;94:85-93.

19. Pereira RF, Halford KW, O'Hara MD, Leeper DB, Sokolov BP, Pollard MD, et al. Cultured adherent cells from marrow can serve as long-lasting precursor cells for bone, cartilage, and lung in irradiated mice. Proc Natl Acad Sci U S A. 1995;92:4857-61.

20. Caplan AI. The mesengenic process. Clin Plast Surg. 1994;21:429-35.

21. Singer JW, Charbond P, Keating A, Nemunaitis J, Raugi G, Wight TN, et al. Simian virus-40 transformed adherent cells from human longterm marrow cultures: clone cells produced with "stromal" and hematopoietic characteristics. Blood. 1987;70:464-74.

22. Shi BQ, Rafii S, Wu MHD, Wijelath ES, Yu C, Ishida A, et al. Evidence for circulating bone marrow-derived endothelial cells. Blood. 1998;92:362-7.

23. Takahashi T, Kalka C, Masuda H, Chen D, Silver M, Kearney M, et al. Ischemia- and cytokine-induced mobilization of bone marrow-derived endothelial progenitor cells for neovascularization. Nat Med. 1999;5:434-4. 